\title{
DEVELOPMENT OF A 50-60 HZ THERMALLY SWITCHED SUPERCONDUCTING RECTIFIER
}

\author{
O.A. Shevchenko, H.H.J. ten Kate, H.J.G. Krooshoop, \\ N.V. Markovsky* and G.B.J. Mulder\#, \\ Applied Superconductivity Centre, University of Twente, \\ P.O. Box 217, 7500 AE Enschede, The Netherlands \\ *Institute of Electrodynamics, Ukraine Academy of Sciences, \\ Pobeda Prospect 56 Kiev 57252680 Ukraine \\ \#Phillips Medical Systems Nederland
}

\begin{abstract}
A full-wave thermally switched superconducting rectifier, able to operate directly from the mains at the $50-60 \mathrm{~Hz}$ frequency, has been developed in our institute. Typical design output values of this device are: current $300 \mathrm{~A}$, voltage up to $1 \mathrm{~V}$, average power up to $100 \mathrm{VA}$ and an efficiency better than $95 \%$. The rectification is achieved by means of fast-response switches and an iron core transformer. A simple and reliable algorithm for the rectifier operation, based on the measured current change across the switches, is developed and tested while powering a small magnet. The new features of the rectifier presented allows for a simplification of the construction and a significant reduction of cost, mass and volume.
\end{abstract}

\section{INTRODUCTION.}

In a superconducting (SC) rectifier phase transition "superconductor-normal metal" is used for rectification. Unfortunately, losses in a rectifier are strongly dependent on it's operation frequency. Due to this a rectifier with efficiency $\geq 95 \%$ usually has an operation frequency lower, than $5 \mathrm{~Hz}$ [1-5]. From the other hand, similar devices operating at the 50 and $60 \mathrm{~Hz}$ with efficiency higher than $80 \%$ are not known.

To combine high operation frequency of the SC rectifier with high efficiency means to simplify substantially it's construction and operation. But for this it is necessary to improve the operation of its main superconducting components: of the switches and of the transformer. Some results of such development are presented in the paper.

The following innovations are realized in the rectifier reported below, determine it's main features:

1. Use of fast-response thermally activated switches controlled by the applied voltage.

2. Use of a non saturated iron core transformer.

3. New current sensors to determine the points of time the secondary current passes zero.

These investigations are supported by The Netherlands Foundation for Fundamental Research on Matter (FOM) as well as by the Ukrainian State Committee on Science and Technology. Manuscript received August 24, 1992.

\section{PRINCIPLES \& THEORY}

\section{A. The principles of operation.}

In Figure 1 the electrical scheme of the rectifier is shown. Here $E_{a}$ is the e.m.f. source, $S_{a}$ is the electronic switch, $\mathrm{R}_{\mathrm{a}}, \mathrm{L}_{\mathrm{a}}$ represent active and inductive resistances of the primary circuit. The SC transformer $\mathrm{p}$

is represented in the scheme by its primary $\mathrm{L}_{p}$ and secondary $L_{1}, L_{2}$ self-inductances while the mutual inductances are not shown. $S_{1}$ and $S_{2}$ are the thermally activated SC switches of the rectifier. $L_{L}$ is the inductance of the SC magnet which is charged but in fact it is not a rectifier element as well as the persistent current switch $\mathrm{S}_{3}$.

The operation of the rectifier switches $S_{1}, S_{2}$ and $S_{a}$ is regulated by a control unit. It is not shown in the figure as well as other additional components such as electrical joints, the sensors to measure the primary and secondary currents, magnet protection system, etc.

The rectifier operation is somewhat different from those described earlier [1-5]. As illustrated in Fig. 2 for the case of inductive commutation (and the sinusoidal input voltage), the operation is cyclic where each half cycle consists of four stages:

1. Opening a switch. A heater pulse is supplied to one switch in order to open it when current across it passes zero (or close to it) in one of the directions.

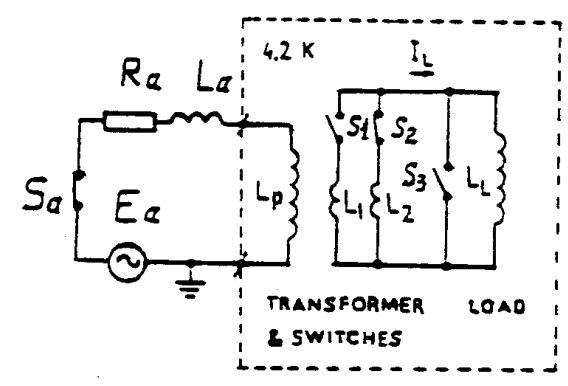

Fig. 1. Basic scheme of the superconducting rectifier. 


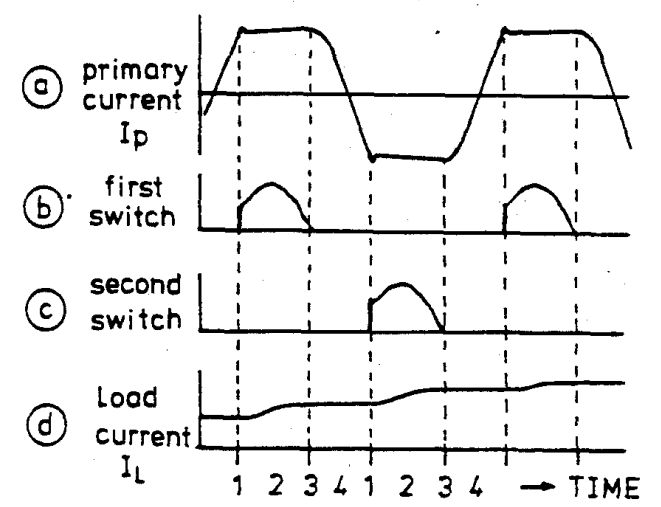

Fig. 2. Diagrams explaining the operation of the rectifier with inductive commutation: a) the primary current, b) the resistance of switch 1 , c) the resistance of switch 2, and d) the current through the load.

2. Pumping. With one switch open due to the permanently generated primary voltage, an increase of the currents in the load $\Delta \mathrm{I}_{\mathrm{L}}$ and primary circuit $\Delta \mathrm{I}_{\mathrm{p}}$ takes place.

3. Closing a switch. From the moment when the voltage across the switch passes zero, it's resistance also becomes zero, and it automatically closes and the recovery starts.

4. Commutation. At the moment that both switches are in the superconducting state due to the applied voltage, inductive commutation starts. In the switch a mixed 'recovery-commutation' process takes place by which simultaneously the gate temperature decreases and the current increases.

Then these four stages are repeated in the second rectifier switch. In the resistive commutation mode, control signals of the switches are generated at the moments when the mains voltage passes zero or close to this value.

\section{B. The theory of operation.}

The theory of the new rectifier is simple and similar to what is previously published [3]. Consider the rectifier with a sinusoidal input voltage, an operation frequency $\omega=2 \pi \times f$, an inductive commutation mode and a load $L_{L}$. A momentary secondary voltage $U_{L}$ ' with amplitude $U_{L O}$ is generated by the transformer:

$$
u_{L}^{\prime}=(\pi / 2) \times \sin (\omega t),
$$

where $u_{L}{ }^{\prime}=U_{L}{ }^{\prime} / U_{L 1}$ and $U_{L 1}=2 \times U_{L O} / \pi$ is a scaling factor.

The output voltage $u_{L}$ of the rectifier during commutation stage $\left(0 \leq \omega t \leq \omega t_{C}\right)$ is equal to the zero. During the following pumping stage $\left(\omega \mathrm{t}_{C} \leq \omega t \leq \pi\right) \mathrm{u}_{\mathrm{L}}$ is equal to $\mathrm{u}_{\mathrm{L}}$ '. The duration of the commutation stage depends on the current in the load $\mathrm{I}_{\mathrm{L}}$ :

$$
\omega t_{C}=\arccos \left(1-2 \times i_{L}\right),
$$

where $i_{L}=I_{L} / I_{m x}, I_{m x}=4 \times U_{L O} /\left(\omega \times L_{c}\right)$ is the theoretical value of the maximum current, $L_{c}$ is the effective secondary inductance of the rectifier during a commutation process.

The average voltage over one cycle $\mathrm{U}_{\mathrm{Lt}}$, applied to the load is:

$$
\mathbf{u}_{\mathrm{Lt}}=\mathbf{1 - \mathrm { i } _ { \mathrm { L } }}
$$

where $\mathrm{u}_{\mathrm{Lt}}=\mathrm{U}_{\mathrm{Lt}} / \mathrm{U}_{\mathrm{Ll}}$. Then, applying Kirchoff's equation to the circuit, the basic formula for the load current during a pumping is obtained:

$$
i_{L}=1-\exp \left(-i_{1} \times n\right)
$$

where $i_{1}=L_{c} L_{L}$, and $n=f \times t=\omega t /(2 \times \pi)$ is the number of rectifier operational cycles. The average output power (over 1 cycle) is:

$$
P_{L t}=U_{L t} \times I_{m x} \times u_{L t} \times i_{L}
$$

The main parameters as introduced above are pictured in Fig. 3 as a function of $i_{1} \times n$ which is linear with time.

\section{DESIGN \& CONSTRUCTION}

The requirements that have to be met for this rectifier are: $50-60 \mathrm{~Hz}$ operation; input current and voltage amplitudes of $\mathrm{I}_{\mathrm{p} 0}=2 \mathrm{~A}$ and $\mathrm{U}_{\mathrm{p}}=150 \mathrm{~V}$ respectively; output current and voltage of $I_{L O}=300 A$ and $U_{L O}=1 V$, the average output power range $P_{L_{A}}=2-100 \mathrm{VA}$, depending on the applied input voltage. Control pulses for the switches

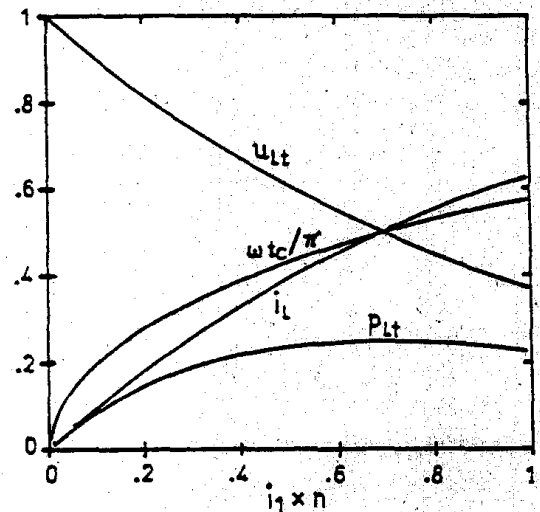

Fig. 3. Rectifier dimensionless output characteristics vs time $i_{1} \times n$ (theory): load current $i_{L}$, average during operation cycle voltage $u_{L t}$, power $p_{L t}$ commutation time $\omega \times t_{e} / \pi$. 
should have a momentary power $\leq 3 \mathrm{~W}$ and a duration $\leq 1 \mathrm{~ms}$. The efficiency has to exceed at least $95 \%$. The rectifier mass and volume must not exceed 10 and $2 \mathrm{~kg}$, 20 and 5 liters for the 'warm' and 'cold' parts respectively. Moreover, the operation and control should be easy and reliable.

'Warm' part.

Accounting for further plans, the 'warm' part has been realized within the mentioned limitations but in fact it is able to drive a one order more powerful 'cold' part (and generate $10 \mathrm{~A}, 300 \mathrm{~V}$ power and $50 \mathrm{~W}, 2 \mathrm{~ms}$ control output signals).

'Cold' part.

The rectifier 'cold' part is built according to the mentioned mass-volume requirements. The main conductors used to built the 'cold' part are specified in Table 2 .

Table 2. Specifications of the conductors

\begin{tabular}{llcl}
\hline Applied in & Material & Bare dimensions Filaments \\
\hline primary & $\mathrm{NbTi} / \mathrm{Cu}$ & $\phi 0.33 \mathrm{~mm}$ & 60 \\
secondary & $\mathrm{Nb}_{3} \mathrm{Sn} / \mathrm{Cu}$ & $10 \times .01 \mathrm{~mm}$ & tape \\
switch $\mathrm{S}_{1}$ & $\mathrm{NbTi}$ & $5 \times .01 \mathrm{~mm}$ & foil \\
switch $\mathrm{S}_{2}$ & $\mathrm{NbTi}$ & $8 \times .01 \mathrm{~mm}$ & foil \\
magnet & $\mathrm{NbTi} / \mathrm{Cu}$ & $\phi 0.7 \mathrm{~mm}$ & 828 \\
\hline
\end{tabular}

The transformer. A cold non-saturated iron core SC transformer (see Fig. 1) has been selected to reduce the applied a.c. voltage and to get an appropriate output current. It's secondary consists of two coil sections, connected in series. An estimation shows that for this case a coupling coefficient $\mathrm{k}=.9996$ can be attained. Therefore the ratio between primary to both secondary turns must be about $\mathrm{I}_{\mathrm{L} 0} / 2 \mathrm{I}_{\mathrm{p} 0}$, i.e. 76. Other important parameters of the transformer are presented in Table 3.

Table 3. Specifications of the transformer

\begin{tabular}{lr}
\hline Primary self-inductance, $\mathrm{L}_{\mathrm{p}}[\mathrm{H}]$ & 4.73 \\
Secondary self-inductances, $\mathrm{L}_{1}, \mathrm{~L}_{2}[\mathrm{mH}]$, each & 0.205 \\
Primary to secondary turns ratio & $760 /(5 \times 2)$ \\
Mutual inductances*, $\mathrm{M}_{\mathrm{p} 1,2 \quad[\mathrm{mH}]} \quad 31.1$ \\
Both secondaries mutual inductance, $\mathrm{M}_{12}[\mathrm{mH}]$ & 0.204 \\
Core magnetic path/crossection, [mm] & $300 /(36 \times 24)$
\end{tabular}

Core saturation current, [mA]

* - between the primary and each secondary

The switches. The fast-response thermally activated switches [6] have been used for a high current-low voltage rectification. The operation of the thermally controlled switches is well known. But the peculiarity of the fast-response switches is that their gate resistance is activated only by a heater pulse in a large number in the gate cross sections and then it is controlled by the applied voltage. The number of initially activated normal zones determines the speed of the switch response when the applied voltage is changing.

The main parameters of the switches are summarized in Table 4. Further details of their operation can be found in reference [6].

\section{RESULTS \& DISCUSSION.}

During the experiments the rectifier has demonstrated a behavior very similar to the usual thyristors based one: if the power voltage and current do not exceed maximum values, control signals are generated in

Table 4. Specification of the switches

\begin{tabular}{|c|c|c|c|}
\hline Switch parameter\Code & $S_{1}$ & $S_{2}$ & $S_{3}$ \\
\hline $\max$. off-resistance, $[\Omega]$ & 0.96 & 1.4 & 10 \\
\hline min. propagation current, $[\mathrm{A}]$ & 2.8 & 1.4 & 0.03 \\
\hline critical current, $[\mathrm{A}]$ & 440 & 336 & $>400$ \\
\hline $\max$. current* at $60 \mathrm{~Hz},[\mathrm{~A}]$ & 440 & 330 & - \\
\hline time constant, $[\mathrm{ms}]$ & 2 & 1.7 & $>1000$ \\
\hline heater active resistance, $[\Omega]$ & 11.7 & 14.9 & 82 \\
\hline
\end{tabular}

correct points of a time and the cooling is well, than its operation is simple, reliable and completely predictable.

Active loads. During tests with a disconnected load and with active loads, an almost rectangular shaped rectifier output characteristic has been obtained. A maximum rectified current of $336 \mathrm{~A}$ and a voltage of $1 \mathrm{~V}$ at the 50 and $60 \mathrm{~Hz}$ is measured with leakage currents close to those (min. prop. curr.) shown in Table 4. The measured values of the self- and mutual inductances of the SC transformer are also in a good agreement with the calculated values (Table 3 )

Inductive load. A number of experimental rectifier characteristics has been obtained during pumping a current into the magnet. A few are presented in Figure 4 and they are in a good agreement with theory.

The maximum available current pumped into the magnet was limited by the magnet quench current of $320 \mathrm{~A}$ at $50-60 \mathrm{~Hz}$ operation. Commutation errors which were higher than expected, have limited the output voltage to $0.6 \mathrm{~V}$. The rectifier operates successfully at frequencies up to $100 \mathrm{~Hz}$, but some decrease of the output parameters have been observed.

Start and stop operations at any current in the magnet, and a change of the output voltage polarity and are reliable features. The resistances of the joints are 


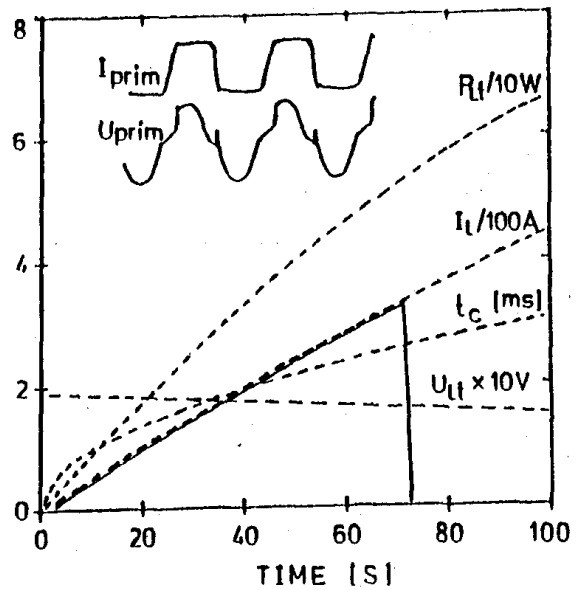

Fig. 4. Rectifier output characteristics vs time: load current $I_{L}$, average voltage $U_{L}$, power $P_{L}$, commutation time $t_{c}$. Dashed lines-theory, solid lines-experiment.

less than $10 \mathrm{n} \Omega$ at $200 \mathrm{~A}$. The rectifier commutation inductance $L_{c}$ is equal to $1.82 \mu \mathrm{H}$ at $300 \mathrm{~A}$ and $50 \mathrm{~Hz}$. .

Based on the experimental data the calculated energy efficiency exceeds $96 \%$ and it can be improved to $97 \%$ if the switches are made equal (see Table 4).

The experiments' demonstrate that the rectifier system is reliable and safe. No changes of the system parameters are found during some runs (which corresponds to more than 2 Megacycles of the operation).

Areas of application. The SC rectifier with an efficiency exceeding $98 \%$ is more preferable for powering magnets with an output voltage $\mathrm{U}_{\mathrm{L}}$ of less than $0.2 \mathrm{~V}$ than any powering system including high current leads. This is caused by the poor efficiency of such leads.

If retracktable leads are not acceptable, then the SC rectifier is more efficient at any output voltage.

The only limitation in this case is, that the ratio between the flux $\Phi_{0}=\mathrm{L}_{\mathrm{L}} \times \mathrm{I}_{\mathrm{L} O}$ stored in the magnet and storage time $t_{0}$ (during which magnet current $I_{L O}$ is constant) not exceeds $0.1 \mathrm{~V}$.

\section{CONCLUSIONS.}

A novel $50-60 \mathrm{~Hz}$ superconducting rectifier, a model for a new generation of similar devices, has been developed. A number of innovations realized determine a successful combination of it's application properties. Particularly, the power control unit is simple and reliable, the 'cold' part is small (less than 5 litres, $2 \mathrm{~kg}$ ) and the device is powerful (up to $100 \mathrm{~W}$ average output power) and efficient.

The maximum efficiency which theoretically can be achieved exceeds $98 \%$. This figure is high enough for the future applications.

The experimental tests at a mains frequencies (50, $60 \mathrm{~Hz}$ ) have demonstrated reliable and fail safe operation of the rectifier up to the magnet quench current of $320 \mathrm{~A}$. At the same conditions the available output voltage range is rather large: from 0.08 to $0.6 \mathrm{~V}$.

Efficiencies exceeding $96 \%$ ('pumping' mode) and $98 \%$ ('current control' mode) when loading a coil have been demonstrated. Further improvements of some rectifier components which are planned in the nearest future, are promising and they can lead to an increase of the efficiency up to $98 \%$ in the 'pumping' mode as well as to an increase of the available output voltage range to the designed range of $0.02-1 \mathrm{~V}$.

\section{REFERENCES}

[1] J. Sikkenga and H.H.J. ten Kate, "A full scale superconducting rectifier for powering an MRI magnet," IEEE Trans. on Magnetics, vol. 25, pp.1771-1774, March 1989.

[2] G.B.J. Mulder, H.H.J. ten Kate, H.J.G. Krooshoop and L.J.M. van de Klundert, "Thermally and magnetically controlled superconducting rectifiers," IEEE Trans. on Magnetics, vol. 25, pp.1819-1822, March 1989.

[3] G.B.J. Mulder, H.H.J. ten Kate, H.J.G. Krooshoop and L.J.M. van de Klundert, "Development of a thermally switched superconducting rectifier for 100 kA," IEEE Trans. on Magnetics, vol. 27, pp.2333-2336, March 1991.

[4] K. Funayama, T. Isono, M. Suzuki, M. Sato and T. Anayama, "Operation of a new-type rectifier fluxpump with saturable core transformer," in Proceedings of the MT-11 Conference, Tsukuba, Japan, 1989, vol.1, pp.461-466, 1990.

[5] T. Ariga and A. Ishiyama, "A two-phase full-wave superconducting rectifier," IEEE Trans on Magnetics, vỏl.25, pp.1815-1818, March 1989.

[6] O.A. Shevchenko, G.B.J. Mulder, N.V. Markovsky, M.A. Fedorovsky and H.H.J. ten Kate, "NbTi foil thermally controlled switches for superconducting converters with operation frequency up to $50 \mathrm{~Hz}$. Parts 1 and 2," papers have been presented at ICEC-ICMC, Kiev, Ukraine, June 1992. 